\title{
Deposition of (111)-Oriented Ag Nano-twinned Film on (111) Si Wafer
}

\author{
Po-Ching $\mathrm{Wu}^{1}$, Pei-Ing Lee ${ }^{1}$, Yu-Chang Lai ${ }^{1}$, Yan-Cheng Lin $^{2}$, Tung-Han Chuang ${ }^{1}{ }^{*}$ \\ ${ }^{1}$ Institute of Materials Science and Engineering, National Taiwan University, 106 Taipei, Taiwan, R.O.C. \\ tunghan@ntu.edu.tw; f07527070@ntu.edu.tw; dajen728728@gmail.com; leepeing@gmail.com \\ ${ }^{2}$ Ag Materials Technology Co., LTD, Hsinchu Science Park, 30078 Hsinchu, Taiwan, R.O.C. \\ yancheng@wiretech.com.tw; tunghan@ntu.edu.tw
}

\begin{abstract}
The special coincidence twin boundary has many advantageous effects for structural and electronic materials. In this study, nano-twinned Ag films with a strong (111) preferred orientation were sputtered on (111) Si substrates with and without a Ti adhesive layer. The proportion of $\Sigma 3$ twin boundaries to the total grain boundaries was $47.2 \%$. The addition of a Ti adhesive layer with a thickness of $0.1 \mu \mathrm{m}$ can effectively reduce the peeling failure of nano-twinned Ag film on (111) Si substrate.
\end{abstract}

Keywords: Nano-twin, Ag sputtering film, (111) Preferred orientation, (111) Si substrate

\section{Introduction}

The innovative concept of grain boundary engineering was proposed by Watanabe [1]. Twin boundaries have a coherent crystal structure with a $\Sigma 3$ coincidence site lattice, which has an interfacial energy of only $5 \%$ of that of the conventional high angle grain boundaries [2]. The beneficial effects of the twin structure on the mechanical properties of structural materials such as Ni-based superalloys [3], austenitic stainless steels [4], and two-phase brass [5] have been shown in many reports. In addition, the Hall-Petch relation in polycrystalline materials is modified due to the presence of twins, as reported by Pande et al.[6]. Lu et al. further found that the high twin density in a pulsed electrodeposited $\mathrm{Cu}$ foil increases the tensile strength to about 10 times that of conventional coarse-grained $\mathrm{Cu}$ specimens, while its electrical conductivity remains comparable to that of pure copper [7,8]. Chen et al. further reported that the interfacial structure and atomic diffusion behaviour of grain boundaries in a $\mathrm{Cu}$ thin film are changed by the twins, which improve its durability against electromigration by one order of magnitude [9]. Since a twin plane has a much lower energy than a conventional high angle grain boundary, the movement of this twin boundary at elevated temperature can be retarded, providing a braking effect on the migration of grain boundaries around the twinned grains. Therefore, the grain growth of this material can be suppressed through the formation of a high density of twins. Chuang et al. reported that a twinned Ag-8Au-3Pd alloy bonding wire for IC and LED packages has a grain structure with superior thermal stability and related material properties [10].

Recently, Liu et al. fabricated (111)-oriented and nano-twinned $\mathrm{Cu}$ film on a Si substrate by DC electroplating [11]. Liu et al. also reported that the $\mathrm{Cu}$ seed layer on the Si substrate played an important role in the regularity of (111)-oriented nano-twinned $\mathrm{Cu}$ film [12]. For the production of a material having a high twin density, an fcc crystal structure and a low stacking fault energy (SFE) are key requirements. Among all the fcc pure metals, Ag possesses the lowest stacking fault energy, about $22 \mathrm{~mJ} / \mathrm{m}^{2}$ [13]. On the other hand, $\mathrm{Cu}$ has a much higher stacking fault energy $\left(70 \mathrm{~mJ} / \mathrm{m}^{2}\right)$ than that of $\mathrm{Ag}$ [14]. It is thus expected that the formation of nano-twinned $\mathrm{Ag}$ film on Si substrate should be easier than that of $\mathrm{Cu}$ film. In fact, Bufford et al. have produced Ag films with (111) and (110) orientations on (111) and (110) Si substrates, respectively, by magnetron sputtering [15]. In their work, the Ag films were deposited directly onto HF etched Si substrates without any adhesive layer at the $\mathrm{Ag} / \mathrm{Si}$ interface. However, our study showed that directly sputtering an $\mathrm{Ag}$ film with a thickness of greater than $2 \mu \mathrm{m}$ on a Si substrate resulted in peeling failure of the Ag film. Additional sputtering of a Ti adhesive layer before the deposition of $\mathrm{Ag}$ film may enhance the $\mathrm{Ag} / \mathrm{Si}$ interface. 


\section{Experimental}

Silver films with thicknesses of $2 \mu \mathrm{m}$ and $9 \mu \mathrm{m}$ were deposited by magnetron sputtering onto silicon substrates with a crystal orientation of (111). Certain specimens were coated with a Ti film with a thickness of $0.1 \mu \mathrm{m}$ before the sputtering of the Ag film. For the sputtering process, the chamber was evacuated to vacuum of $5 \times 10^{-6}$ Torr and then filled with argon to $5 \times 10^{-3}$ Torr. The deposition rates of the $\mathrm{Ag}$ and Ti films were $0.9 \mathrm{~nm} / \mathrm{s}$ and $0.1 \mathrm{~nm} / \mathrm{s}$, respectively, for the sputtering power of $150 \mathrm{~W}$. After the $\mathrm{Ag}$ and Ti films were sputtered on the (111) Si substrates, the specimens were prepared for microstructure observations by focused ion beam (FIB). The crystal orientation of the surfaces of the sputtered Ag films was identified by X-ray diffraction (XRD). The cross-sectional microstructure of the nano-twins in the sputtered Ag films was further observed with TEM, and the crystal structure was identified by selected area diffraction (SAD) taken from the TEM specimens. In addition, the crystal orientation and the density of the nano-twins were analysed by electron backscatter diffraction (EBSD). To compare the cohesion between sputtered Ag films and (111) Si substrates with and without the Ti adhesive layer, a grid peeling test was conducted.

\section{Results and Discussions}

Figure 1 shows the microstructure of the cross-section of a Si/Ag specimen prepared by focused ion beam (FIB). It can be seen that many Ag columnar grains grew normal to the (111)-oriented Si substrate. These Ag grains consisted of a high density of nano-twins piled up on each other. The XRD spectrum of the sputtered Ag film on (111) Si substrate showed a strong $\mathrm{Ag}$ (111) peak with very weak $\mathrm{Ag}(200)$ and $\mathrm{Ag}$ (311) peaks. However, it was found that the sputtered Ag film on (111) Si peeled off easily when the thickness of the Ag film was greater than $2 \mu \mathrm{m}$. This result indicated that the adhesion between the nano-twinned film and the (111) Si substrate was insufficient.

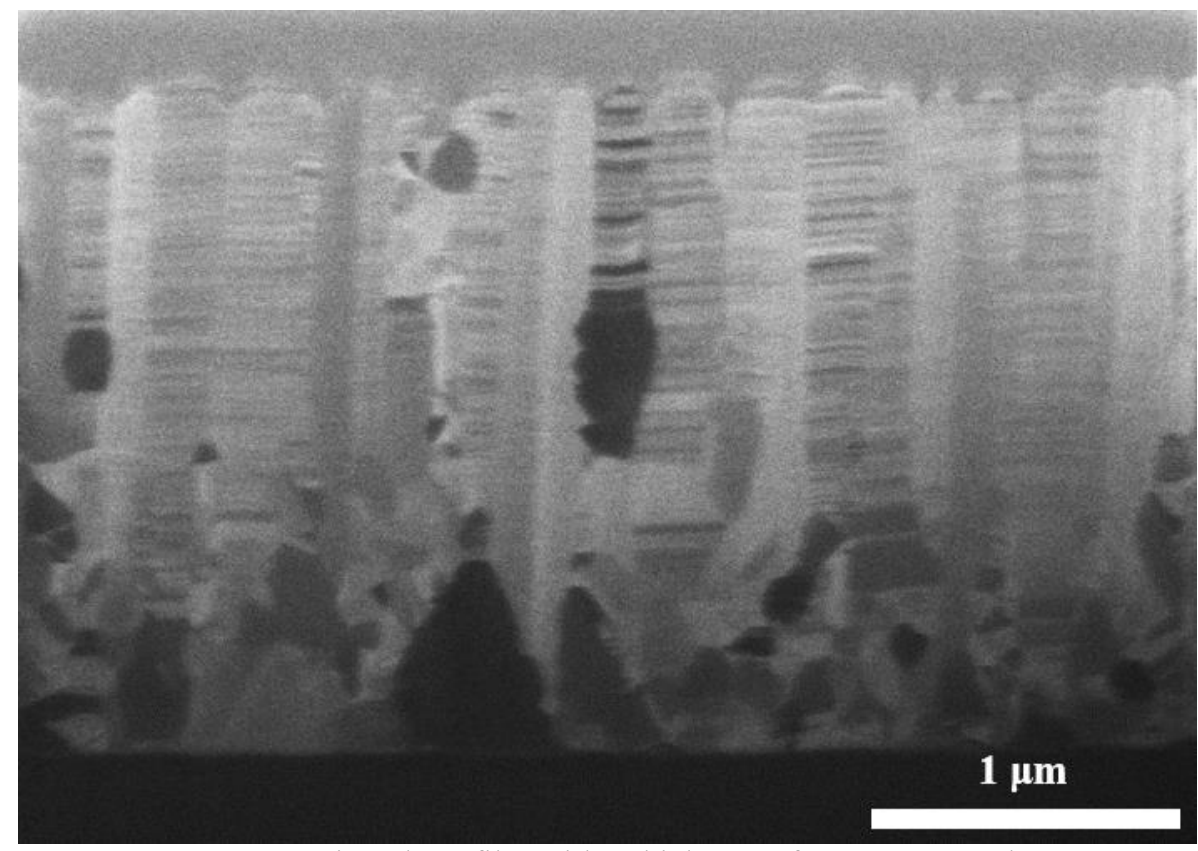

Fig. 1: Microstructure of nano-twinned Ag film with a thickness of $2 \mu \mathrm{m}$ sputtered on a (111) Si substrate. 


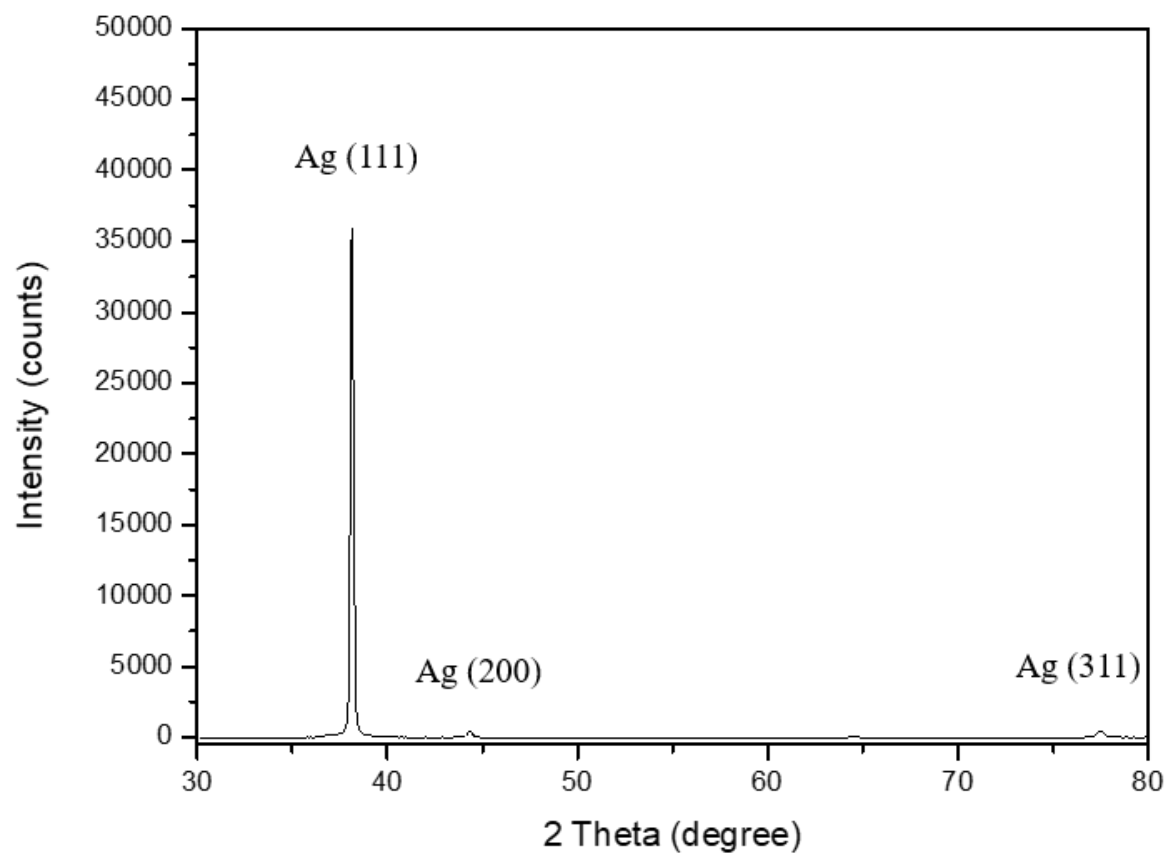

Fig. 2: XRD spectra of sputtered Ag film with a thickness of $2 \mu \mathrm{m}$ sputtered on a (111) Si substrate.

To improve the bonding effect of the nano-twinned $\mathrm{Ag} /(111) \mathrm{Si}$ interface, an adhesive film Ti of $0.1 \mu \mathrm{m}$ thickness was sputtered on the (111) Si substrate before the deposition of nano-twinned Ag film. In this case, the Ag film on the surface of the Ti-coated (111) Si substrate could be much thicker than the Ag film directly sputtered on Si without the Ti adhesive layer. As shown in Fig. 3, the Ag columns grew normal to the (111) Si substrate, similarly to those observed in Fig. 1. The columnar Ag grains also contained a high density of nano-twins. The XRD spectrum showed a pure Ag (111) peak, indicating that these nano-twinned Ag film had a very strong (111) preferred orientation.

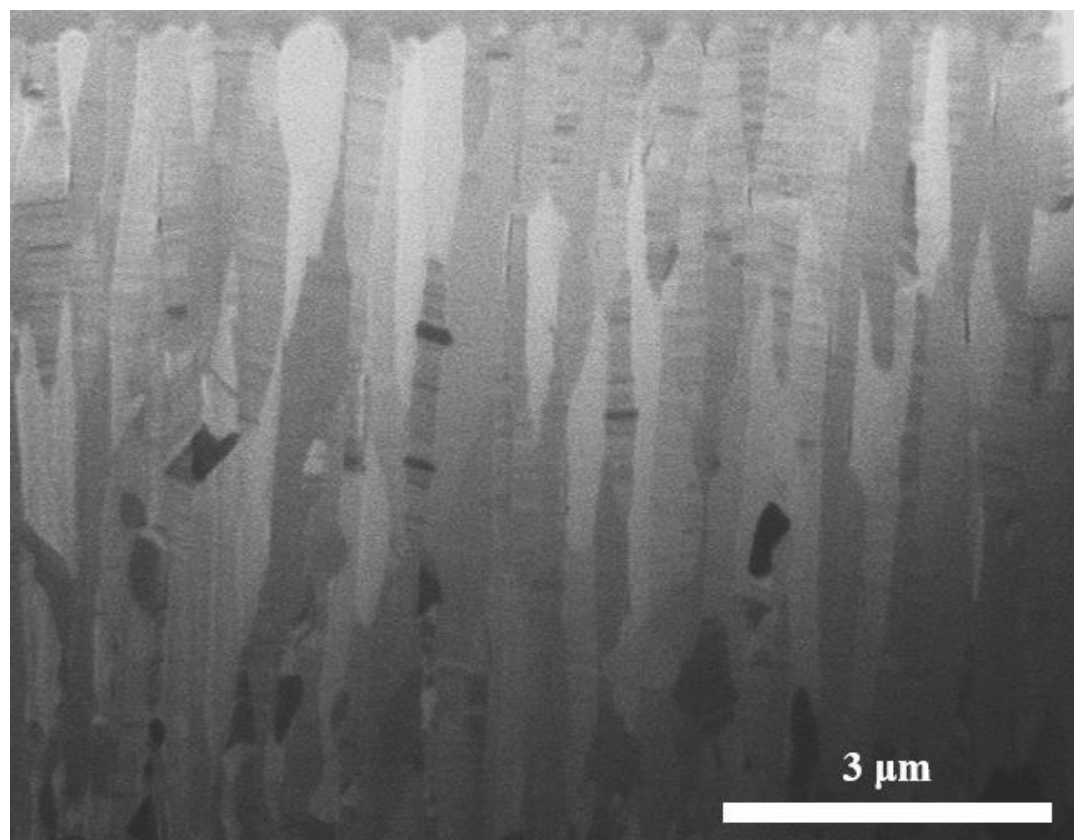

Fig. 3: Microstructure of nano-twinned Ag film with a thickness of $9 \mu \mathrm{m}$ on a $0.1 \mu \mathrm{m}$ Ti-coated (111) Si substrate. 


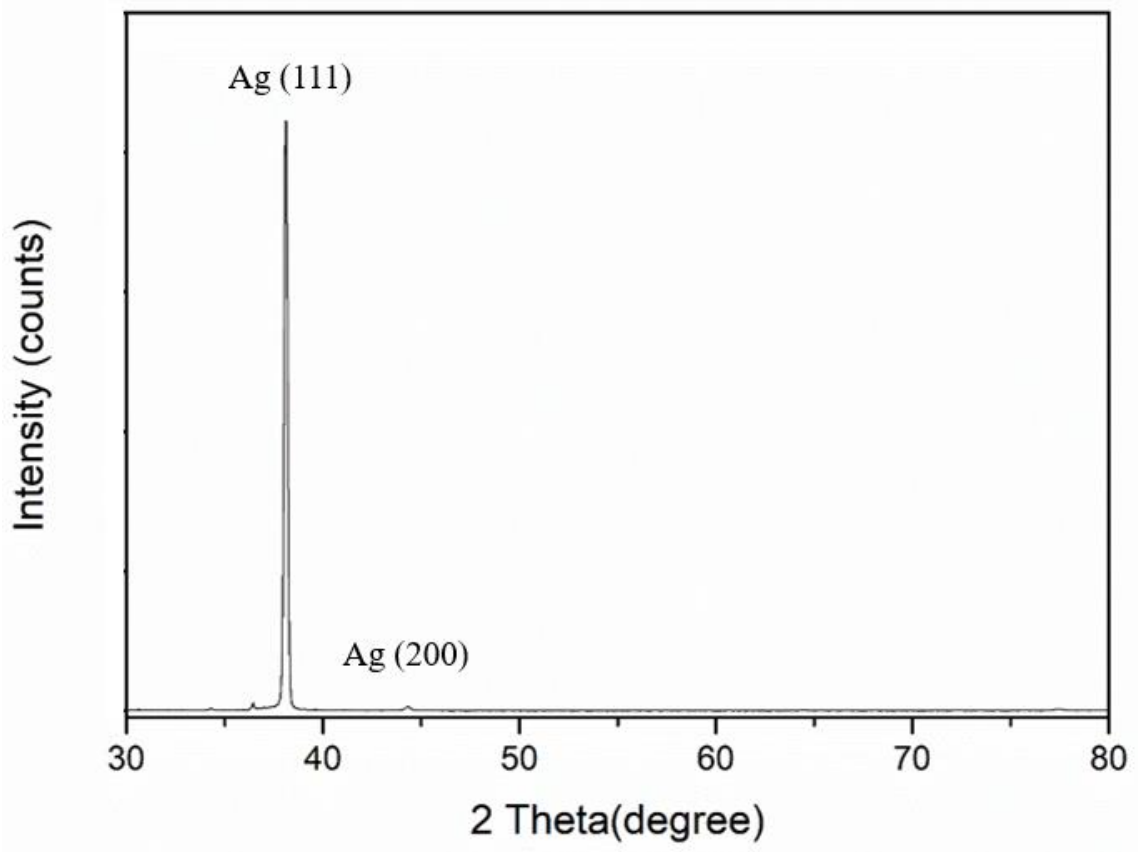

Fig. 4: XRD spectra of sputtered Ag film with a thickness of $9 \mu \mathrm{m}$ on a $0.1 \mu \mathrm{m}$ Ti-coated (111) Si substrate.

Figure 5 presents a TEM micrograph of the nano-twinned Ag film. The cross-section SAD patterns of the Ag grains revealed an fcc single crystal structure with a high density of (111)-oriented nano-twins. The spacings of these twins ranged from 5 to $50 \mathrm{~nm}$, with an average value about $16 \mathrm{~nm}$. The Ag nano-twins were further identified by electron backscatter diffraction (EBSD). It can be seen in Fig. 6 that the columnar Ag grains grew primarily along the (111) direction. The average grain size of these Ag columns was $0.17 \mu \mathrm{m}$. The proportions of $\Sigma 3$ and $\Sigma 9$ coincidence twin boundaries to the total grain boundaries were $47.2 \%$ and $16.2 \%$, respectively.

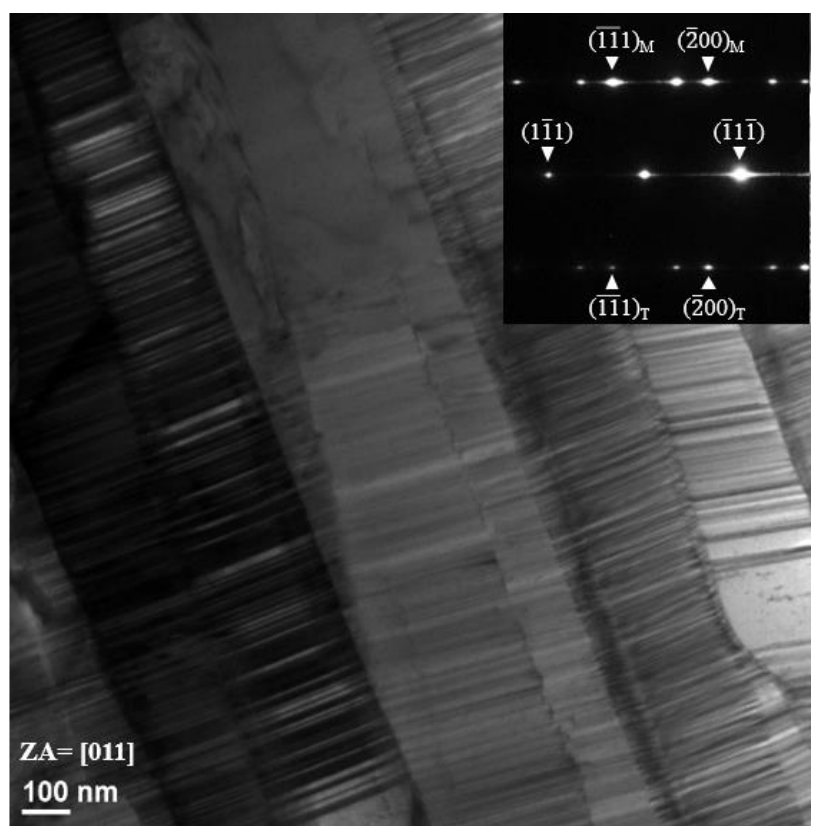

Fig. 5: TEM micrograph of nano-twinned Ag film with a SAD pattern. 


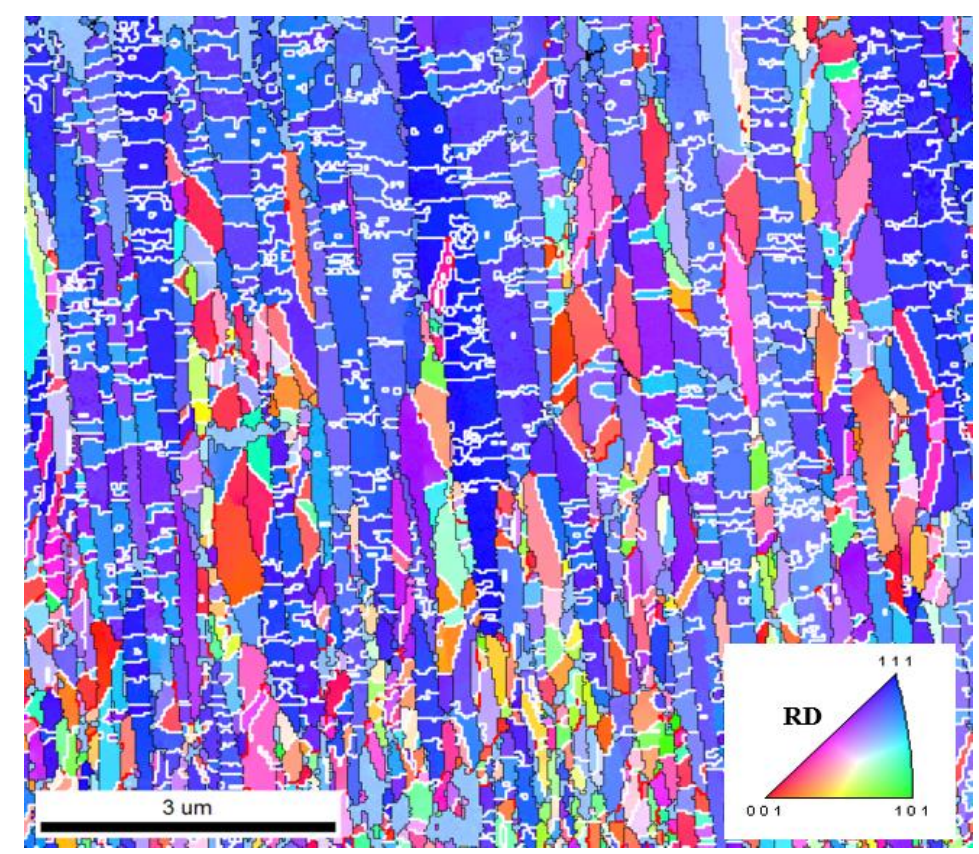

Fig. 6: EBSD analysis of the nano-twinned $\mathrm{Ag}$ film with a crystal orientation pole figure.

The cohesion of nano-twinned (111) Ag film on the (111) Si substrate with and without a Ti adhesive layer was evaluated using a grid peeling test. Figure 7 shows that, with no Ti adhesive layer, the sputtered Ag film with a thickness of only $2 \mu \mathrm{m}$ peeled off the (111) Si substrate. With a $0.1 \mu \mathrm{m}$ Ti adhesive layer inserted between the nano-twinned (111) Ag film and the (111) Si substrate, the Ag film with a thickness of $9 \mu \mathrm{m}$ exhibited no failure after the peel test, as evidenced in Fig. 8. The results confirm that the addition of a Ti adhesive layer can effectively strengthen the $\mathrm{Ag}-\mathrm{Si}$ interface and improve the deposition quality of nano-twinned (111) Ag film on (111) Si substrate.

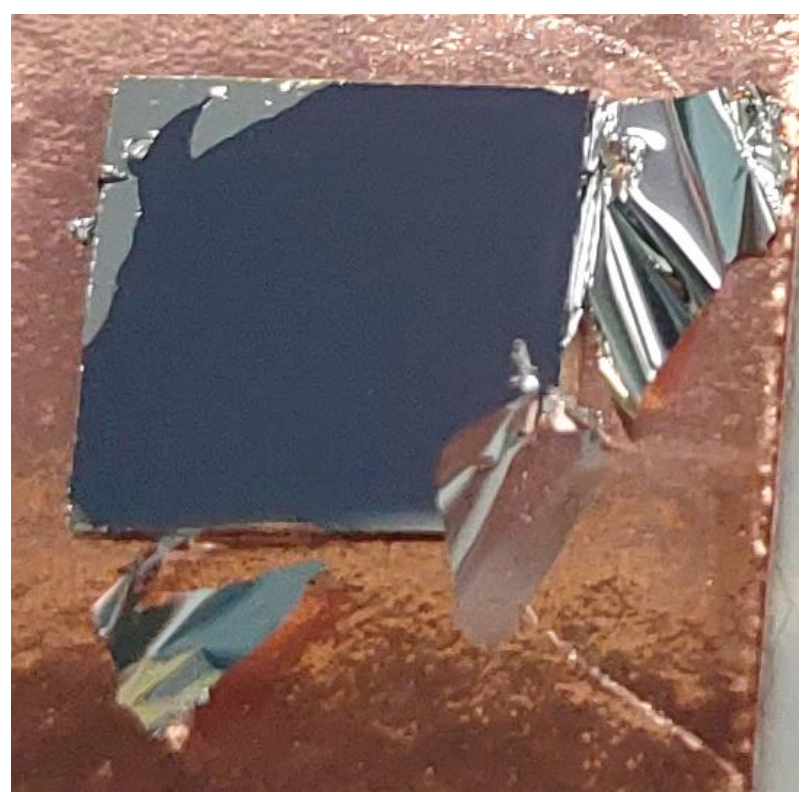

Fig. 7: Peeling test of the nano-twinned (111) Ag film with a thickness of $2 \mu \mathrm{m}$ on a (111) Si substrate without a Ti adhesive layer. 


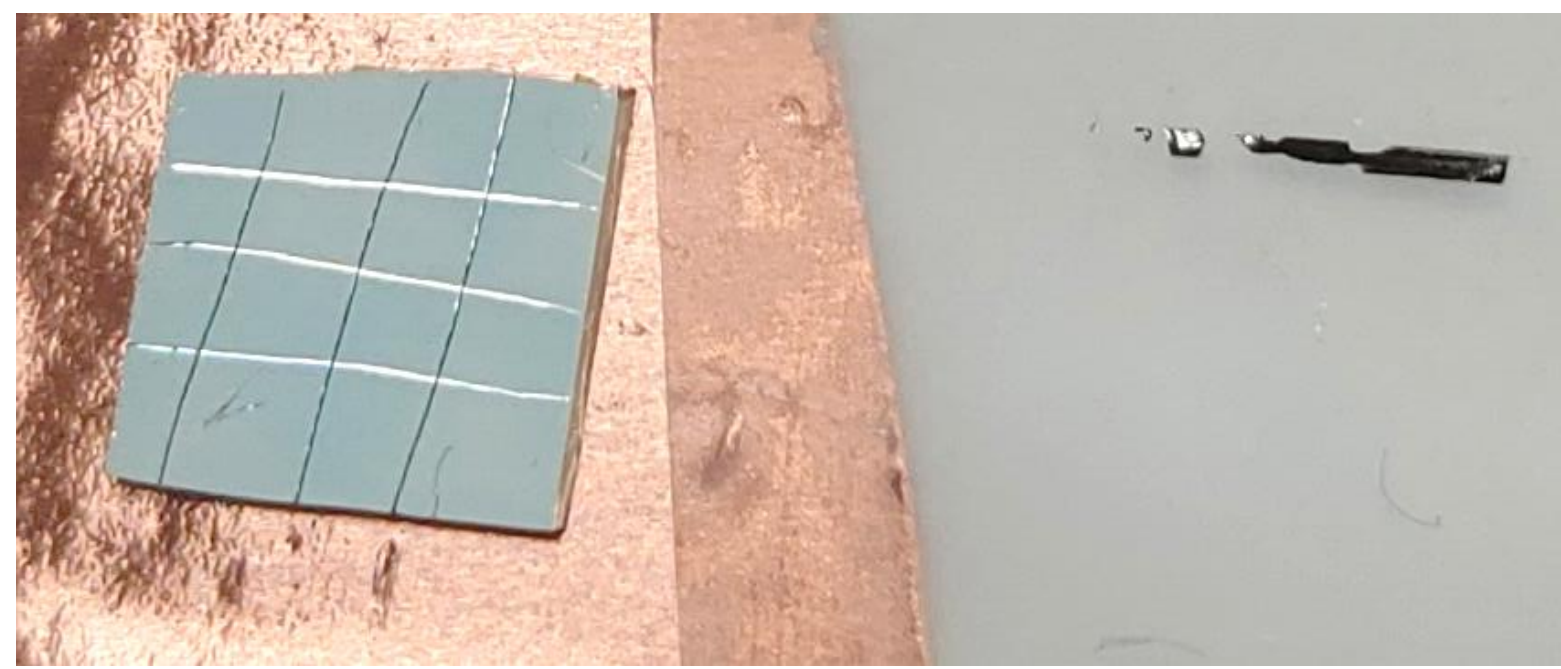

Fig. 8: Peeling test of the nano-twinned (111) Ag film with a thickness of $9 \mu \mathrm{m}$ on a $0.1 \mu \mathrm{m}$ Ti-coated (111) Si substrate.

\section{Conclusions}

Ag films with a high density of nano-twins on (111)-oriented Si substrates have been fabricated by magnetron sputtering. The Ag nano-twins revealed a strong (111) preferred orientation. The Ag grains were observed to grow normal to the (111) Si substrates in a columnar morphology with a diameter of about $0.17 \mu \mathrm{m}$. It was also found that directly sputtering the Ag film on the (111) Si substrate caused peeling failure when the thickness of the Ag film was greater than $2 \mu \mathrm{m}$. The addition of a Ti adhesive layer with a thickness of $0.1 \mu \mathrm{m}$ can obviously enhance the bonding effect of sputtering nano-twinned (111) Ag film on (111) Si substrates.

\section{Acknowledgements}

This study was sponsored by the industrial and academic cooperation programs of Wire Technology Co. LTD. and the Ministry of Science and Technology, Taiwan, under Grant No. MOST 108-2622-E002-009-CC2.

\section{References}

[1] T. Watanabe, "An approach to grain boundary design for strong and ductile polycrystals," Res. Mech., vol. 11, pp. 47-84, 1984.

[2] R.W. Cahn, in Physical Metallurgy, North Holland, 1970, p.1184.

[3] N. Souai, N. Bozzolo, L. Naze, Y. Chastel, R. Loge, “ About the possibility of grain boundary engineering via hotworking in a nickel-base superalloy," Scripta Mater., vol. 62, pp. 851-854, 2010.

[4] S. Mandal, A.K. Bhaduri, V.S. Sarma, "Studies on twinning and grain boundary character distribution during anomalous grain growth in a Ti-modified austenitic stainless steel," Mater. Sci. Eng., vol. A 515, pp. 134-140, 2009.

[5] S. Lee, Y.B. Chun, J.W. Hua, S.K. Hwang, "Effect of thermomechanical processing on grain boundary characteristics in twophase brass," Mater. Sci. Eng., vol. A 363, pp. 307-315, 2003.

[6] C. Pande, B. Rath, M. Imam, "Effect of annealing twins on Hall-Petch relation in polycrystalline materials," Mater. Sci. Eng., vol. A 367, pp. 171-175, 2004.

[7] L. Lu, Y. Shen, X. Chen, L. Qian, K.Lu, "Ultrahigh strength and high electrical conductivity in copper," Science, vol. 304, pp. 422-426, 2004.

[8] L. Lu, X. Chen, X. Huang, K.Lu, “ Revealing the maximum strength in nanotwinned copper," Science, vol. 323, pp. 607-610, 2009.

[9] K.C. Chen, W.W. Wu, C.N. Liao, L.J. Chen, K.N. Tu, Science, vol. 321, pp. 1066-1069, 2008.

[10] T.H. Chuang, H.C. Wang, C. H. Tsai, C.C. Chang, C.H. Chuang, J.D. Lee, H.H. Tsai, "Thermal stability of grain structure and material properties in an annealing- twinned Ag-8Au-3Pd alloy wire," Scripta Mater., vol. 67, pp. 605608, 2012. 
[11] T.C. Liu, C.M. Lin, H.Y. Hsiao, C.L. Lu Y.S. Huang, C. Chen, "Fabrication and characterization of (111)-oriented and nanotwinned $\mathrm{Cu}$ by DC electrodeposition," Crystal growth design, vol. 12, pp. 5012-5016, 2012.

[12] T.C. Liu, H.W. Lin, C.L. Lu, C. Chen, "Effect of grain orientations of $\mathrm{Cu}$ seed layers on the growth of (111)oriented nanotwinned Cu," Scientific Reports, 4: 6123, DOI: 10.1038/srep06123, 2014.

[13] R. Meyer, L.J. Lewis, "Stacking-fault energies for Ag, Cu, and Ni from empirical tight-binding potentials," Physical Rev., vol. B 66, p. 052106, 2002.

[14] I.L. Dillamore, R.E. Smallman, W.T. Roberts, "A determination of the stacking-fault energy of some pure FCC metals," Philo. Mag., vol. 9, pp. 517-526, 1964.

[15] D. Bufford, H. Wang, X. Zhang, " High strength, epitaxial nanotwinned Ag films,” Acta Mater., vol. 59, pp. 93-101, 2011. 